www.jmscr.igmpublication.org Impact Factor 5.84

Index Copernicus Value: 83.27

ISSN (e)-2347-176x ISSN (p) 2455-0450

crossref DOI: _https://dx.doi.org/10.18535/jmscr/v5i5.28

Journal Of Medical Science And Clinical Research

An official Publication of IGM Publication

\title{
Comparison of Pure Tissue Repair (Desarda) and Prosthetic Repair (Lichtenstein) Methods for Inguinal Hernia Repair
}

\author{
Authors \\ Dr Rushabh Shah, Dr Pankaj B. Bharadva, Dr Manan Shah, \\ Dr Jigar Shah
}

Resident Doctor, Dept of General Surgery, Govt Medical College Baroda, Vadodara, India Corresponding Author

Dr Pankaj B. Bharadva

Address: "Shree Krishna Kutir”, Ghandhinagar Society, Keshod-362220

Contact no.:+919426846211 Email: pankajbharadva@gmail.com

\section{ABSTRACT}

Background: The surgical treatment of inguinal hernias has evolved through several stages to reach a modern and successful era. Though Lichtenstein's prosthetic repair using prolene mesh has been popular lately, it is not a tissue based repair and hence cannot be consider ideal. Hence a search for ideal hernia repair is still underway and Desarda Procedure might be the procedure satisfying the criteria for an ideal hernia repair. It is simple, easy to learn and based on the concept of providing a strong, mobile and physiologically dynamic posterior inguinal wall.

Settings and Design: This is a comparative study carried out in 56 patients, out of which 28 underwent Lichtenstein's repair and 28 underwent Desarda repair, admitted in surgical ward in Sir Sayajirao Hospital, Baroda.

Materials and Methods: Data was collected by meticulous history taking, careful clinical examination, appropriate radiological, haematological investigation, operative findings and followup of the cases

Results: After 6 months follow up only 3.6\% patients had chronic groin pain compared to $10.7 \%$ in Mesh repair. The postoperative pain is lesser with Desarda technique and patients ambulate faster. There was no recurrence seen in both groups during the 6 months follow-up period.

Conclusion: Desarda repair is superior to mesh repair in short term outcomes and in certain long term outcomes like chronic groin pain.

Keywords: Desarda repair, Lichtenstein's repair, Inguinal hernia, Post operative pain. 


\section{Introduction}

It has been said that the history of groin hernias is the history of surgery itself. ${ }^{1}$ Hernia repair is one of the most commonly performed general surgical procedures worldwide. ${ }^{2}$ Since the time Bassini described his technique the search for an Ideal Inguinal Hernia repair is still on. An Ideal Hernia repair should be Tension free, Tissue based, with no potential damage to vital structures, no Long Term pain or complications and no recurrence. Lichtenstein's prosthetic repair using prolene mesh has been popular lately $\&$ it is a tension free repair. The mesh works as a mechanical barrier, but it does not give mobility and physiologically dynamic posterior wall ${ }^{3}$ Moreover this technique is associated with risk of infections, recurrence, chronic pain testicular atrophy and infertility, foreign body sensations and chronic groin sepsis which sometimes may require mesh removal. ${ }^{4}$ Other tissue repairs like such as modified Bassini, Iliotibial tract repair, Shouldice, Nylon-Darn, Halsted-Tanner, McVay and many others either require good surgical experience or are tension repairs fraught with recurrences.

Suture repair for inguinal hernia is still under development, and recently, Desarda has described an operation where a 1-2 cm strip of external oblique aponeurosis lying over the inguinal canal is isolated and then sutured to the conjoint tendon and inguinal ligament, reinforcing the posterior wall of inguinal canal. ${ }^{5}$ This new technique is theoretically closer to ideal hernia repair. It is based on the concept of providing a strong, mobile and physiologically dynamic posterior inguinal wall. It does not require complicated dissection or suturing. There is no tension on the suture line. It does not require any foreign material and does not use weakened muscles or transversalis fascia for repair.

The purpose of this study is thus to attempt to establish the influence of this new technique on early clinical outcomes of inguinal hernia repair, and limited study of long term outcomes. If proved to be effective it will be a basis for the promotion of its use globally.

\section{Material and Method}

This is a Single Centre, Randomized ,comparative study carried out in 56 patients admitted in surgical ward in Sir Sayajirao Hospital, Baroda from October 2014 to March 2016 with a follow up period of 6 months. Male patients above 18 years of age with a primary, unilateral, reducible inguinal or inguino-scrotal hernia were included in this study. Patients with bilateral inguinal hernia, obstructted or strangulated inguinal hernia, previous abdominal surgery, local skin infection, Females and age less than 18 years were excluded. The type of procedure the patient is to undergo was decided only during the surgery by placing the patient in respective treatment group according to the computer generated randomization chart. 
The patients having good condition of EOA were then divided into two groups, Group- L included 28 patients in whom Prolene MESH was used i.e. Lichtenstein's Procedure and Group -D included 28 patients in whom NO MESH was used i.e underwent pure tissue repair using External Oblique Aponeurosis i.e. Desarda Repair.

The features of good condition of EOA are as follow:

1. EOA should be strong membranous like structure.

2. The fibers of EOA should be directed downwards \& medially.

3. The fibers should be closely aggregated together.

4. The fibers should extend obliquely across from the anterior superior iliac spine to the pubic tubercle nd the pectineal line.

5. The fibres should not tear away when held with stout artery forceps.

Purpose of the study and the methods of treatment were carefully explained to the patients individually and written informed consent taken.

Detailed history was collected including age, chief complaints and duration, other associated conditions like chronic cough, chronic constipation, urinary complaints etc, history of previous abdominal surgeries, family history, occupation, marital status etc. Detailed physical examination was conducted by any experienced surgeon. Telephonic contact numbers and detailed address were collected for follow up.

All patients underwent surgery under spinal anaesthesia. In Lichtenstein hernioplasty a 3 inch x 6 inch polypropylene mesh made by same company was used in all cases. The mesh was $0.5 \mathrm{~mm}$ thick and has burst strength of approximately $14 \mathrm{~kg} / \mathrm{cm}^{2}$. Polypropylene 1-0 was used to suture the mesh in place. In Desarda repair an un-detached strip of the external oblique aponeurosis (EOA) is sutured to the inguinal ligament below and the muscle arch above, behind the cord, to form a new posterior wall using polydiaxanone no. 1 in continuous manner. [fig:1-4] One dose of same antibiotic i.e. Inj. Ceftriaxone $1 \mathrm{gm}$ intravenously was given for all patients half an hour prior to the surgery. Post operatively analgesia in the form of Inj. Diclofenac single dose and then Tab. Diclofenac 50mg twice a day for next 2 days was given.

Operating time was measured as the time of total procedure i.e. starting from the skin incision till the final suture taken for skin closure. The patients were followed up for postoperative pain which was evaluated using Visual Analogue Scale, wound hematoma, seroma, wound infection, scrotal swelling, chronic pain and foreign body sensation. Time for return to routine light sedentary job work as done by the patient pre-operatively, postoperative duration of hospital stay and recurrence rate was also documented. Patients were discharged if there was no wound infection, were ambulatory, were 
taking orally, felt comfortable and requested for discharge. Sutures were removed on the $8^{\text {th }}$ to $10^{\text {th }}$ postoperative day.

Descriptive and inferential statistical analysis has been carried out in the present study.

Significance is assessed at $5 \%$ level of significance.

The Statistical software namely SAS 9.2, SPSS 15.0, Stata10.1, MedCalc 9.0.1, Systat 12.0 and R environment ver.2.11.1 were used for the analysisof the data and Microsoft word and Excel have been used to generate graphs, tables etc.

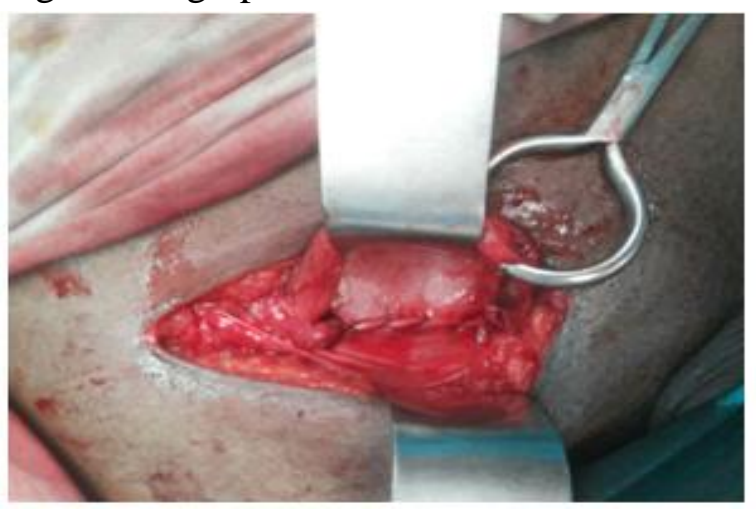

Figure-1: Suturing of Upper Leaf of external Oblique to Inguinal Ligament

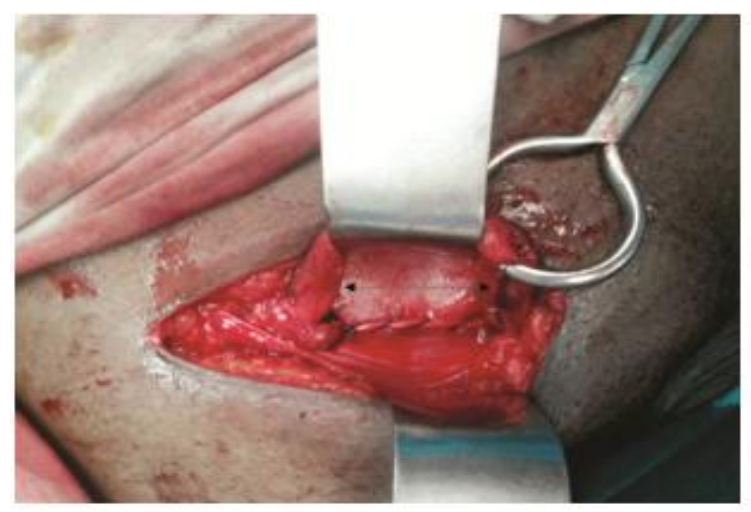

Figure-2: Incision on sutured upper leaf of External Oblique and creation of Strip of external oblique for repair

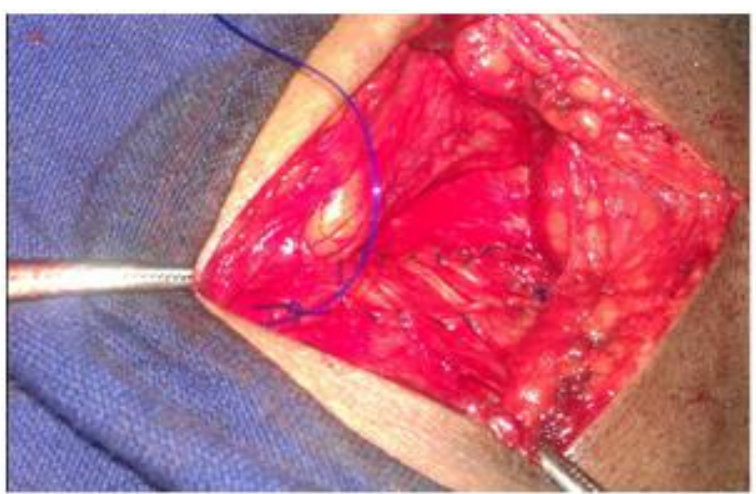

Figure-3: Upper end of Undetached external oblique strip sutured to conjoint tendon

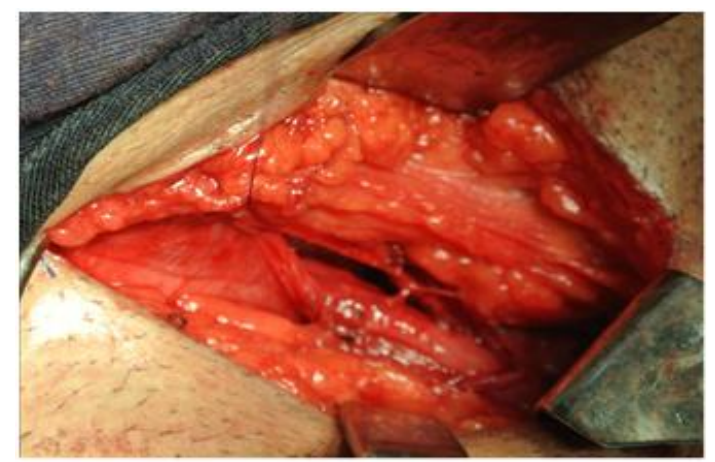

Figure-4: Closure of external oblique over the inguinal canal with the cord structures inside.

\section{Results and Discussion}

The mean age of presentation in Lichtenstein group was $48.57 \pm 15.8$ years and in Desarda group was $40.82 \pm$ 14.51 years. The study had $\mathrm{P}$ Value of 0.06 , which was similar on comparison with other groups and literature.

Swelling was the most common presentation with most patients presenting within 1-3 months. Pain was present in $54.1 \%$ was also correlating well with other studies $3,6,7,8$. 
The present study, direct hernia $78.6 \%$ and indirect in $21.4 \%$ in Lichtenstein group and $57.14 \%$ direct and $42.86 \%$ indirect in Desarda group. The P Value is 0.17 which showing both the groups are comparable.

The incidence of direct inguinal hernia is more in our study. This distribution varied from other studies with indirect type being most common ${ }^{9,12}$. More than 2/3rd of patients have indirect type of hernia. However, there is no absolute correlation regarding this variable in all the studies overall. $^{3,6}$

Inguinal hernias are more common on right side. The cause may be because of delayed descent of the right testicle. The present study shows $64.3 \%$ right, $35.7 \%$ left hernia in Lichtenstein group and $60.72 \%$ right and $39.28 \%$ left hernia in Desarda group. The $\mathrm{P}$ values are not significant, both the groups are comparable and the results are similar to the literature $9,10,11,12$.

The mean duration of the total surgery in Lichtenstein group was $74.68 \pm 2.86$ mins while that in Desarda Group was $64.43 \pm 2.59$ mins. There was a statistically significant difference of nearly 10 minutes with a $\mathrm{P}$ value of $<0.0001$. Youssef et al and Rodriguez et al in their study found statistical difference between the two groups in operative time whereas $\mathrm{Z}$ Abbas et al and Mitura et al did not found any statistical difference ${ }^{11,12,13,14}$.

On POD 1 the mean VAS Score in Lichtenstein Group was 5.93 \pm 1.12 , while that in Desarda Group was $4.39 \pm 1.03$ though the difference is small it is still statistically significant with a $\mathrm{P}$ value of $<0.0001$. Similar findings are reported by $\mathrm{Z}$ Abbas et $\mathrm{al}^{14}$.

On POD 7 the present study has a mean pain score of $2.07+1.30$ in Lichtenstein group and $0.61+0.88$ in Desarda group. It was statistically significant.

Comparison of Complications in two groups of patients studied.(Table-1)

\begin{tabular}{|l|c|c|c|c|}
\hline Complications & Group L & Group D & Total & P value \\
\hline Normal & $18(64.3 \%)$ & $21(75 \%)$ & $39(69.6 \%)$ & 0.56 \\
\hline Fever & $2(7.1 \%)$ & $1(3.6 \%)$ & $3(5.4 \%)$ & 0.99 \\
\hline Seroma & $2(7.1 \%)$ & $3(10.7 \%)$ & $5(8.9 \%)$ & 0.99 \\
\hline Scrotal swelling & $4(14.2 \%)$ & $2(7.1 \%)$ & $6(10.7 \%)$ & 0.67 \\
\hline Hematoma & $1(3.6 \%)$ & $0(0 \%)$ & $1(1.8 \%)$ & 0.99 \\
\hline Wound Infection & $1(3.6 \%)$ & $1(3.6 \%)$ & $2(3.6 \%)$ & 1 \\
\hline Total & $28(100 \%)$ & $28(100 \%)$ & $56(100 \%)$ & ---- \\
\hline
\end{tabular}

Not Significant, Chi Square Test.

The overall incidence of chronic groin pain in Lichtenstein group was $14.3 \%$ while that in Desarda group was 3.6\%.

The overall incidence of foreign body sensation in Lichtenstein group was
$14.3 \%$ while that in Desarda group was $0 \%$. It is not statistically significant $(\mathrm{P}=0.49)$.

No recurrence in inguinal hernia was seen in patients of both the Lichtenstein and 
Desarda groups during the 6 months follow up period.

The mean duration of Postoperative Hospital stay in Lichtenstein group was $5.39 \pm 1.89$ while that in Desarda Group was $3.96 \pm 1.85$, with a statistically significant difference of 1.43 days with a $P$ value of 0.0061 .

The mean duration (in days) to return to the routine light sedentary job work (occupation) was $7.43 \pm 1.73$ in the Lichtenstein group and $5.25 \pm 1.17$ in the Desarda group. On statistical calculation the $\mathrm{P}$ Value is $<0.0001$, which is considered statistically significant. Our findings are consistent with the literature $9,12,14,15$.

\section{Conclusion}

The present study was done to compare two different surgical procedures for Inguinal hernia repair, namely Lichtenstein's mesh repair and No Mesh Desarda repair using external oblique aponeurosis.

Desarda repair was superior to Lichtenstein's repair in terms of operating time, post-operative pain, time for return to routine light sedentary job work, hospital stay and incidence of chronic pain. However further studies and longer follow-up are needed to comment on recurrences.

\section{References}

1. Ostrow B, Guelph. What is the Most Appropriate Repair for Groin Hernias in Africa? Surgery in Africa. Canada 2006.

2. Kingsnorth A, LeBlanc K (2003) Hernias: inguinal and incisional. Lancet 362(9395):1561-1571.

3. Desarda MP. Physiological repair of inguinal hernia-A new technique (study of 860 patients). Hernia. 2006;10:143-146.

4. Fitzgibbons, Robert J. (2005). "Can We Be Sure Polypropylene Mesh Causes Infertility?". Annals of Surgery 241 (4): 559-6.

5. Stephen J Nixon, Bruce Tulloh. (2014), Bailey and Love's Short Practice of Surgery; 26th edition. Edited by N. S. Williams, C. J. K. Bulstrode and P. R. O'Connell . Boca Raton, FL: CRC Press, 2013. P.957-8.

6. Desarda M, Ghosh A: Comparative Study of Open Mesh Repair and Desarda's Nonmesh Repair in a District Hospital in India. East and Central Africa $n$ Journal of Surgery. 2006; 11(2):28-34.

7. Desarda MP: Surgical Physiology of Inguinal Hernia Repair - a Study of 200 Cases. BMC Surgery 2003; 3 .

8. Situma MS: Comparison of Desarda and Modified Bassini Inguinal Hernia Repair in Mulago Hospital. Kampala: Makerere University 2008.

9. Manyilirah W, Kijjambu S, Upoki A, Kiryabwire J. Comparison of non-mesh (Desarda) and mesh 
(Lichtenstein) methods for inguinal hernia repair among black African patients: a short-term double-blind RCT. Hernia. 2012; 16 (2): 133--144.

10. Szopinski J, Dabrowiecki S, Pierscinski S, Jackowski M, Jaworski M, Szuflet Z. Desarda versus Lichtenstein technique for primary inguinal hernia treatment: 3-year results of a randomized clinical trial. World $\mathrm{J}$ of surgery. 2012; 36 (5): 984--992.

11. P.R.l. Rodríguez, P.P. Herrera, O.L. Gonzalez, J. R.C. Alonso, H.S.R. Blanco. ISSN 2073-9990 East Cent. Afr. J. surg July/August; 2013 Volume 18 (2).

12. Youssef T, El-Alfy K, Farid M. Randomized clinical trial of Desarda versus Lichtenstein repair for treatment of primary inguinal hernia. Int J Surg. 2015 Aug; 20:28-34. doi: 10.1016/j.ijsu.2015.05.055. Epub 2015 Jun 11.

13. Mitura K, Romanczuk M (2008). Comparison between two methods of inguinal hernia surgery Lichtenstein and Desarda. Pol Merkur Lekarski 24:392-395.

14. Zaheer Abbas, Sujeet Kumar Bhat, Monika Koul, Rakesh Bhat. Desarda's no mesh repair versus lichtenstein's open mesh repair of inguinal hernia: a comparative study.
DOI:10.14260/jemds/2015/1910. J of Evolution of Med and Dent Sci/ eISSN-2278-4802,pISSN-22784748/ Vol. 4/ Issue77/Sept 24, 2015.

15. Desarda MP (2008) No-mesh inguinal hernia repair with continuous absorbable sutures: a dream or reality? A study of 229 patients. Saudi J Gastro 14:122127. 